\title{
Simultaneous observation of ionospheric plasma bubbles and mesospheric gravity waves during the SpreadFEx Campaign
}

\author{
H. Takahashi ${ }^{1}$, M. J. Taylor ${ }^{2}$, P.-D. Pautet ${ }^{2}$, A. F. Medeiros ${ }^{3}$, D. Gobbi ${ }^{1}$, C. M. Wrasse ${ }^{4}$, J. Fechine ${ }^{3}$, M. A. Abdu ${ }^{1}$,

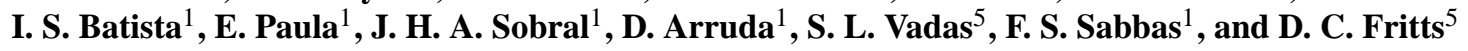 \\ ${ }^{1}$ Instituto Nacional de Pesquisas Espaciais (INPE), São José dos Campos, Brazil \\ ${ }^{2}$ Center for Atmospheric and Space Science, Utah State University, Logan, Utah, USA \\ ${ }^{3}$ Universidade Federal de Campina Grande (UFCG), Campina Grande, Brazil \\ ${ }^{4}$ Universidade de Vale do Paraíba (UNIVAP), São José dos Campos, Brazil \\ ${ }^{5}$ Colorado Research Associates (CoRA), Boulder, USA
}

Received: 15 April 2008 - Revised: 26 January 2009 - Accepted: 26 January 2009 - Published: 2 April 2009

\begin{abstract}
During the Spread F Experiment campaign, under NASA Living with a Star (LWS) program, carried out in the South American Magnetic Equator region from 22 September to 8 November 2005, two airglow CCD imagers, located at Cariri $\left(7.4^{\circ} \mathrm{S}, 36.5^{\circ} \mathrm{W}\right.$, geomag. $\left.11^{\circ} \mathrm{S}\right)$ and near Brasilia $\left(14.8^{\circ} \mathrm{S}, 47.6^{\circ} \mathrm{W}\right.$, geomag. $\left.10^{\circ} \mathrm{S}\right)$ were operated simultaneously and measured the equatorial ionospheric bubbles and their time evolution by monitoring the airglow OI 6300 intensity depletions. Simultaneous observation of the mesospheric $\mathrm{OH}$ wave structures made it possible to investigate the relationship between the bubble formation in the ionosphere and the gravity wave activity at around $90 \mathrm{~km}$. On the evening of 30 September 2005, comb-like OI 6300 depletions with a distance of $\sim 130 \mathrm{~km}$ between the adjacent ones were observed. During the same period, a mesospheric gravity wave with a horizontal wavelength of $\sim 130 \mathrm{~km}$ was observed. From the 17 nights of observation during the campaign period, there was a good correlation between the OI 6300 depletion distances and the gravity wave horizontal wavelengths in the mesosphere with a statistically significant level, suggesting a direct contribution of the mesospheric gravity wave to plasma bubble seeding in the equatorial ionosphere.
\end{abstract}

Keywords. Atmospheric composition and structure (Airglow and aurora) - Ionosphere (Ionospheric irregularities)

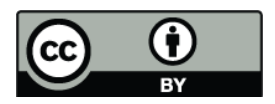

Correspondence to: $\mathrm{H}$. Takahashi (hisaotak@laser.inpe.br)

\section{Introduction}

Earth's equatorial ionosphere has two specific characteristics compared to the middle and high latitude ionosphere, namely, the Equatorial (Appleton) Anomaly and Equatorial Spread F (ESF). These two processes are not independent from each other. The evening pre-reversal enhancement of the zonal electric field causes F-layer uplifting. The vertical drift frequently produces Rayleigh-Taylor Instability (RTI) in the bottom side of the layer, resulting in the Spread F development. The bottom side Spread F frequently develops to higher altitude and extends along the magnetic field line toward the low to middle latitude, both in the Northern and Southern Hemispheres, forming plasma bubbles (Abdu, 2001). The plasma bubbles have zonal extension of a few tens of $\mathrm{km}$ and extend along the magnetic field line to hundreds or thousands of km depending on their developing altitude (Sobral et al., 2002). A vertical extension of the bubble is variable from tens of $\mathrm{km}$ to hundreds of $\mathrm{km}$. (Labelle et al., 1997; Muralikrishna and Abdu, 2006). The factor that decides the vertical extension is not well known yet.

Atmospheric gravity waves are normally generated through the process of vertical movement of air-parcel forced by convections, front activity and topography in the troposphere and wind shear instability in the mesosphere (Holton, 1992; Alexander et al., 1997; Fritts and Alexander, 2003). It is produced under a balance of the buoyancy and gravity forces. Once the oscillation is generated, it propagates horizontally and vertically transporting energy and momentum. As a result, the wind, density and temperature fields are perturbed. The amplitudes of these oscillations increase exponentially with height because of the exponential decrease of

Published by Copernicus Publications on behalf of the European Geosciences Union. 
the atmospheric density. The condition of vertical propagation and dissipation of the waves depends on the wave characteristics (wavelength and phase velocity) and the filtering by the background wind system. In the equatorial mesopause region $(80$ to $100 \mathrm{~km}$ ), the gravity waves with a period of 5 to $30 \mathrm{~min}$, horizontal wavelength of 10 to $100 \mathrm{~km}$, phase velocity of $20-80 \mathrm{~m} / \mathrm{s}$, are frequently observed by airglow imaging method (Wrasse et al., 2006). Some of these waves have a condition to propagate above $100 \mathrm{~km}$, even up to $200 \mathrm{~km}$ in the ionosphere (Vadas and Fritts, 2004). The horizontal and vertical oscillations of the air-parcel in the ionosphere generate the movement of ions and electrons under the earth's geomagnetic field, resulting in plasma density perturbation along the magnetic field line and induced electric field. This could lead to the seeding of the plasma instability by RTI mechanism that can trigger the formation of plasma bubbles, which has been studied extensively (e.g., Hysell et al., 1990; Fritts et al., 2009; Abdu et al., 2009).

The seeding mechanism of RTI and the development process of the plasma bubble have called special attention for investigation. The coupling of the ionospheric plasma dynamics and neutral atmosphere wave dynamics have been extensively studied in the last 30 years (Abdu, 2001). However, it seems that a conclusive scenario for explaining the ionosphere-atmosphere coupling dynamics, as related to spread $\mathrm{F}$ development, has not yet been drawn. Röttger (1973) first presented wave-like structures of the equatorial Spread F irregularities and called attention to its possible relation with the lower atmosphere dynamics. Woodman and LaHoz (1976) presented results suggesting the role of gravity waves in modulation of the plasma density and electric fields and in seeding the RTI. Later, Röttger $(1977,1981)$ studied possible coupling mechanism between the lower and upper atmosphere and suggested that the tropospheric convective systems, which generate gravity waves and thunderstormgenerated electric fields, could be responsible for the generation of ESF. From the Backscatter power spectrum obtained by Jicamarca Radio Observatory, Hysell et al. (1990) found periodic oscillation of the backscatter power in the bottom side of the F-layer, with a $\sim 50 \mathrm{~km}$ of horizontal distance. They concluded that this must be caused by a propagating gravity wave in the thermosphere. However, no further observation, for example of the neutral winds, to confirm this hypothesis has been carried out. McClure et al. (1998) presented, in a statistical form, correlations between the ESF and tropical convections from satellite data. Recently Ogawa et al. (2006) compared ionospheric scintillations and Earth's black body temperatures over the Indian Ocean and found a correlation between them, indicating a possibility of dynamical coupling from the troposphere to the ionosphere.

It seems that the role of the lower atmosphere dynamical activities (gravity waves, tides and winds) in the plasma bubble formation is today well discussed. However, very little work has reported direct evidence on the bubble seeding by specific dynamical event in the lower atmosphere
(Fritts et al., 2008a; Abdu et al., 2009). The purpose of the present work is, therefore, to investigate direct evidence of the plasma bubble formation and mesospheric gravity wave activities. For this purpose, simultaneous measurements of the bubbles and mesospheric gravity waves have been carried out by using airglow all-sky imagers observing the OI $630.0 \mathrm{~nm}$ and OHNIR emissions. Any similarities between the gravity wave parameters (horizontal wavelength) and bubble structures (distance) would be investigated. Ionospheric parameters obtained by a digisonde and a VHF coherent radar are used to compare the optical image data.

\section{Instruments and observation}

\subsection{SpreadFEx Campaign}

The First SpreadFEx Campaign was carried out from September to November 2005, as a part of the NASA Living with a Star Program. The main purpose of the campaign was to investigate possible effects of gravity waves on the seeding of ionospheric bubbles in the equatorial region. Several USA and Brazilian institutes participated in this campaign, with coordinated ground-based observations using digisondes, all-sky imagers, meteor- and VHF-radars and GPS receivers. The satellite TIMED/GUVI and SABER data were also used. The purpose of the campaign and some results are summarized in a paper by Fritts et al. (2009) in this issue. Two airglow CCD imagers, one located near Brasilia $\left(14.8^{\circ} \mathrm{S}, 47.6^{\circ} \mathrm{W}\right.$, geomag. $\left.10^{\circ} \mathrm{S}\right)$ and another at Cariri $\left(7.4^{\circ} \mathrm{S}, 36.5^{\circ} \mathrm{W}\right.$, geomag. $\left.11^{\circ} \mathrm{S}\right)$ were operated simultaneously and measured the equatorial ionospheric bubble structures and their time evolution by monitoring the OI $630 \mathrm{~nm}$ all-sky images. The observation sites are shown in Fig. 1. The site near Brasilia is located South-West (SW) of Cariri at a distance of $\sim 1500 \mathrm{~km}$. The two sites are approximately at the same magnetic latitude.

\subsection{Airglow all-sky imager at Cariri}

An all-sky imager, with a 180 degree wide-angle fish-eye lens followed by a telecentric lens system and narrow band optical filters, was used to get a monochromatic image on a CCD camera. For the present study, 4 optical filters to measure the airglow OI $557.7 \mathrm{~nm}$, OI $630.0 \mathrm{~nm}$ (hereafter “6300"), OHNIR (715-930 nm) and background continuum at $570 \mathrm{~nm}$ were used. A wide area $(2.5 \times 2.5 \mathrm{~cm}) \mathrm{CCD}$ camera, with $1024 \times 1024$ pixels and thermoelectrically cooled $\left(-36^{\circ} \mathrm{C}\right)$, was mounted. The 6300 image was measured with a time integration of $90 \mathrm{~s}$, while the OHNIR was measured with $15 \mathrm{~s}$ of time integration. Each filter was repeated at an interval of about $5 \mathrm{~min}$. The 6300 image covers a horizontal extension of $\sim 1500 \mathrm{~km}$ (at the zenith angle of $75^{\circ}$ ) at an altitude of $250 \mathrm{~km}$, permitting to estimate the latitudinal and longitudinal extension and zonal separation of the depletions, in addition to the zonal drift velocity. 


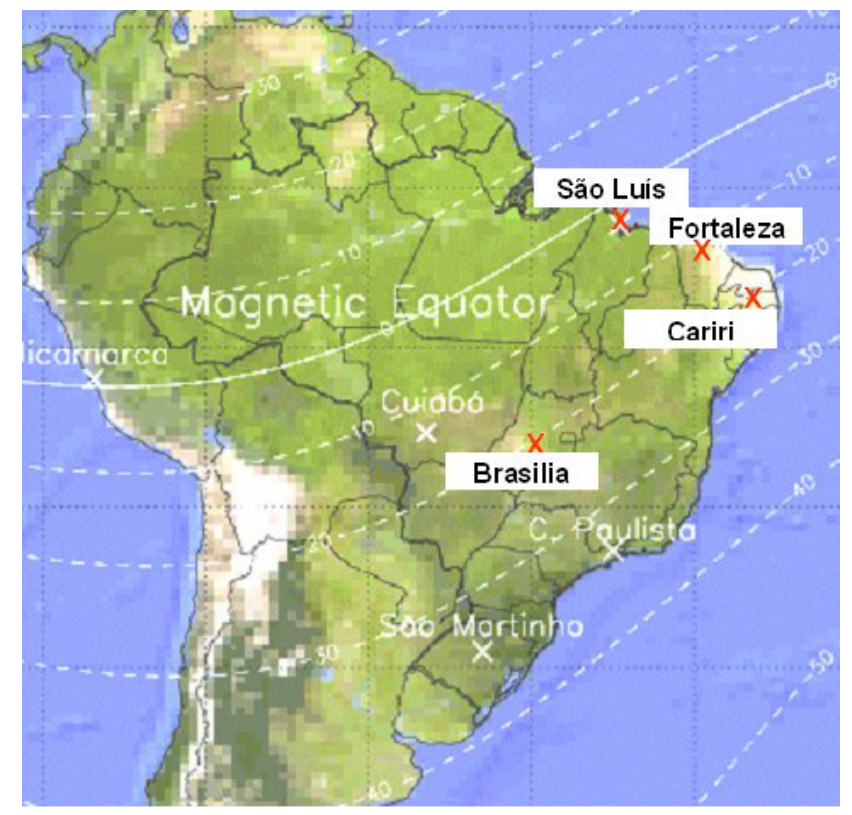

Fig. 1. Map of Dip latitude over the South America and SpreadFEx campaign observation sites.

The OHNIR images show spatial irregularity of the $\mathrm{OH}$ emission rate produced mainly by the passage of internal gravity waves in the emission layer at around $90 \mathrm{~km}$. The field of view of the OHNIR image is around $800 \mathrm{~km}$ (at $\sim 80^{\circ}$ zenith angle). For image analysis, the FFT power spectrum was used to find out the characteristics of the wave motions. For the waves with a longer horizontal wavelength ( $>200 \mathrm{~km}$, for example) the FFT analysis did not work well. In this case, the "Keogram" technique was adapted. The wind structure in the mesopause region from 80 to $99 \mathrm{~km}$ was monitored by a meteor radar (SkiYmet) at Cariri.

\subsection{Digisondes at São Luís and Fortaleza}

Ionospheric parameters were measured at São Luís $\left(2.6^{\circ} \mathrm{S}\right.$, $\left.44.2^{\circ} \mathrm{W}\right)$ and Fortaleza $\left(3.9^{\circ} \mathrm{S}, 38.4^{\circ} \mathrm{W}\right)$ by a Digital ionospheric sounder (Digisonde Portable Sounder, DPS-4). This is a wide-band coded pulsed radar system with $500 \mathrm{~W}$ peak power and a fast-switching frequency synthesizer, covering a frequency range from 0.5 to $30 \mathrm{MHz}$. Ionograms are taken with a 10-min observational interval. The true heights at fixed frequencies (1 to $8 \mathrm{MHz}$ ) from the sequence of ionograms are used. Fortaleza is located NW of Cariri at a distance of $450 \mathrm{~km}$, and São Luís is located in approximately the same direction but $1000 \mathrm{~km}$ away from Cariri. For the present analysis, a VHF coherent scatter radar at São Luís was also used that provides Range-Time-Intensity-RTI maps of the back-scattered echoes from the 5-m size spread F irregularities.

The airglow imager provides the spatial structure of the OI 6300 emission intensity which corresponds to the plasma

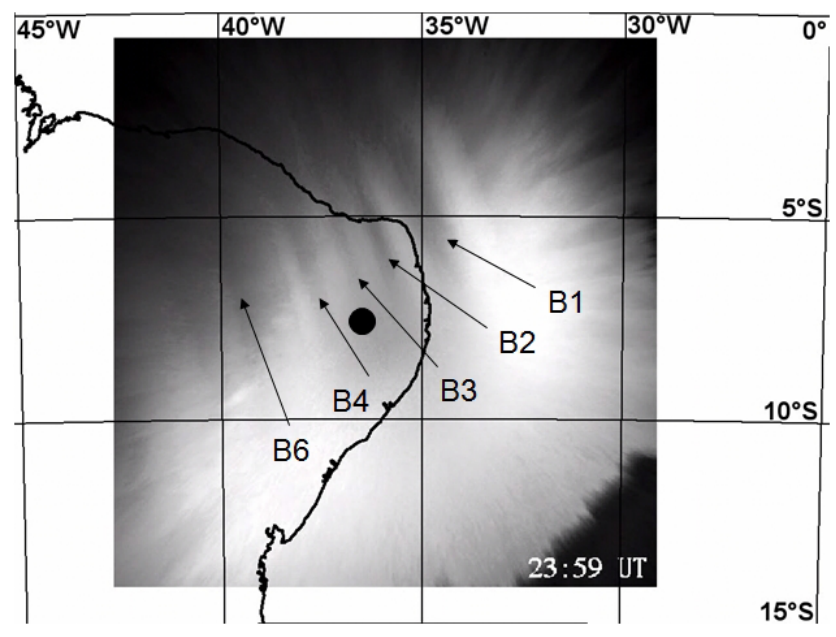

Fig. 2. OI 6300 Flatfield image taken at Cariri in the night of 30 September 2005, at 23:59 UT (20:59 LT). The black dot is the location of the observation site. The OI 6300 intensity depletions are numbered (see Fig. 5).

density variations and thus provides information on plasma depletions. The image is a two-dimensional ionosphere map at an altitude of around 250 to $280 \mathrm{~km}$. No precise information of the emission height is available. The digisonde measures the F-layer density height distribution and the vertical drift, and the VHF coherent radar observes the height distribution of the ionospheric irregularities. Therefore, the simultaneous observation of the ionospheric irregularity by three different methods provides information on the ionospheric plasma depletions in a three-dimensional form. In addition to the ionosphere monitoring, the OHNIR images provide the characteristics of the gravity wave propagating in the 80 to $100 \mathrm{~km}$ region.

\section{Results}

The SpreadFEx campaign observation started on 22 September 2005 and continued up to the end of November 2005. Optical observation was concentrated in two periods around the new moon period, the first phase from 22 September to 10 October and the second phase from 26 October to 8 November 2005. A total 26 nights of image observations were carried out. For the present study, 17 nights of image data with better sky conditions were selected and analyzed, and two nights were chosen for detailed analysis.

\subsection{September 2005}

In the evening of 30 September 2005, a group of short extended comb-like 6300 depletions were observed at 22:54 UT (19:54 LT). The depletions drifted eastward like plasma bubbles, but without developing in the N-S directions. Figure 2 shows a 6300 flat-field image taken at Cariri at 

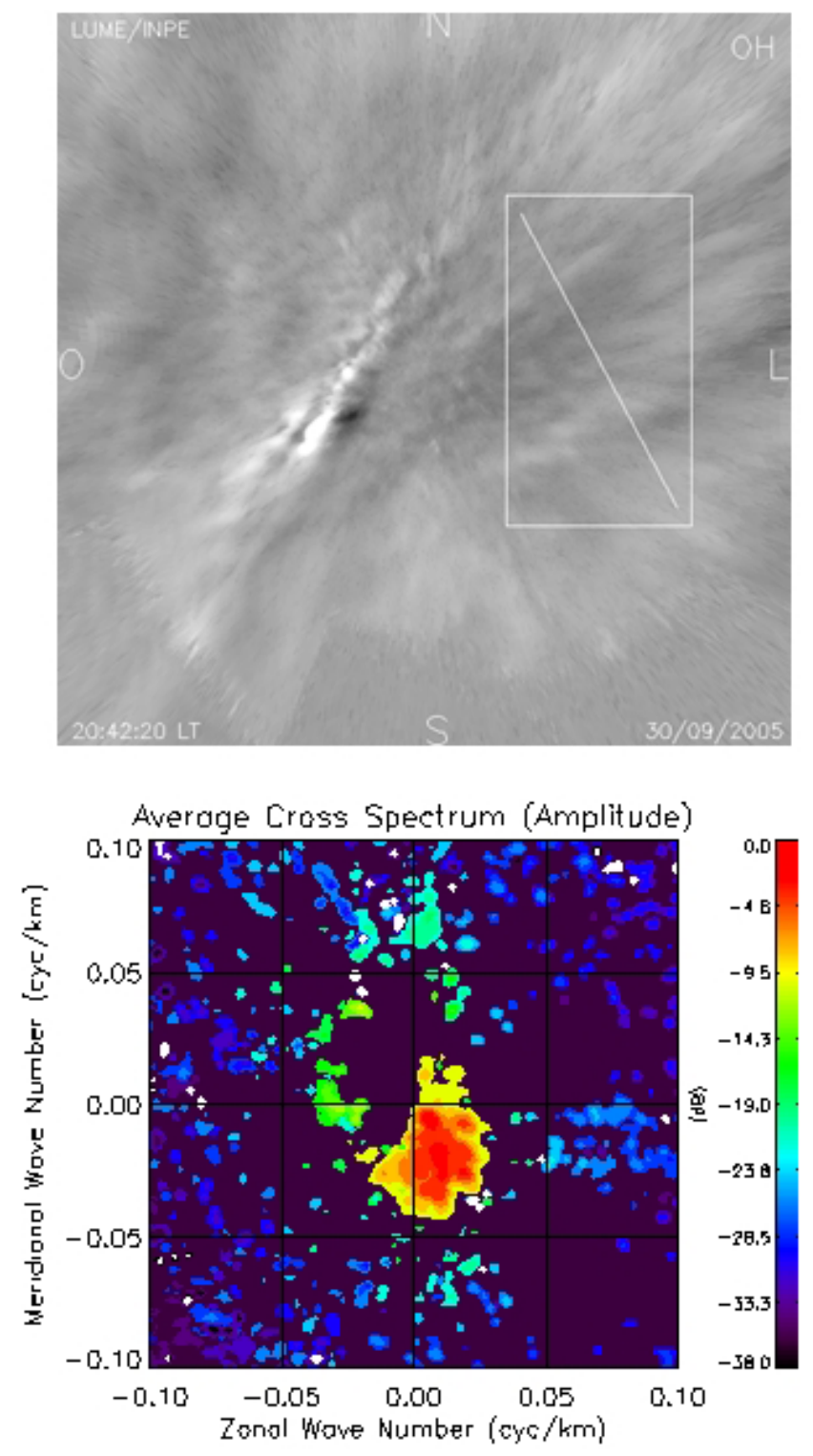

Fig. 3. OHNIR Flatfield image taken at Cariri in the night of 30 September 2005, at 23:42 UT (20:42 LT) (top), and the 2D-FFT spectrum (bottom). The rectangular area indicates where to analyze wave characteristics by FFT. The diagonal line indicates the direction of wave propagation in consideration. The line shaped bright blob in the center of image is the Milky way.

23:59 UT. The image covers more than $1500 \mathrm{~km}$ of extension. The black dot in the center of the image marks Cariri site (zenith). Almost equi-distant OI 6300 depletions can be seen in the northern sky. The numbers in the figure indicate the sequence of the depletions. It seems that they are extended along the magnetic field lines, as plasma bubbles are. The average distance between the depletions is $\sim 130 \mathrm{~km}$. The depletions drifted eastward and disappeared from the imager view in the eastern side, but new depletions came into the view from the northwestern side. After 00:20 UT, one of the

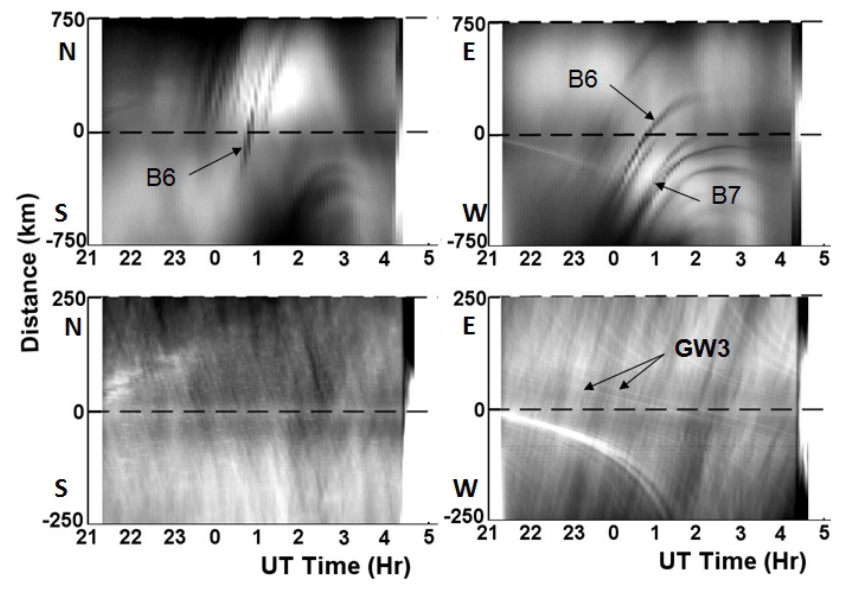

Fig. 4. Keogram of the flatfield images of OI 6300 (top) and OHNIR (bottom) at Cariri on 30 September 2005: N-S cut (leftside) and EW cut (rightside).

depletions started to extend in the meridional direction and reached over the zenith. The apex height of the geomagnetic field line passing in the northwestern sky of Cariri (geomag. $11^{\circ} \mathrm{S}$ ) at an altitude of the OI 6300 emission layer (around $250 \mathrm{~km}$ ) is around $300 \mathrm{~km}$ of altitude at the magnetic equator. The apex height becomes $500-600 \mathrm{~km}$ for the field line intersecting the zenith direction over Cariri. It means that the first group of the plasma depletions maintained their altitude around $300 \mathrm{~km}$, and later it developed upwards reaching around $500 \mathrm{~km}$. The latter one has typical plasma bubble characteristics, but the former ones did not show all of the characteristics of plasma bubbles.

During the same period between 23:00 and 24:00 UT, the $\mathrm{OH}$ emission images (OHNIR) from the mesopause region $(\sim 90 \mathrm{~km})$ showed a wavelike structure propagating from NW to SE. Figure 3 shows a OHNIR flat-field image taken at 23:42 UT. The area marked by a rectangle shows where to see the wave structure and a diagonal line indicates the direction of propagation. The FFT 2-D spectrum, also shown in the figure, indicates that a long wave with the horizontal wavelength of $\sim 130 \mathrm{~km}$ is propagating toward SE. The extended bright blobs over the zenith are the milky way.

Figure 4 shows Keograms of the 6300 images in the N$\mathrm{S}$ (top, left) and E-W directions (top, right) as a function of time. The first few depletions before 24:00 UT can be seen only in the northern sky. After 00:30 UT a well developed (meridionally extended) bubble (B6) appeared over the zenith and drifted toward the east. Then, the other extended bubbles can be seen in the western sky but not reaching the zenith. The zonal drift velocity was reduced after 01:00 UT approaching the local midnight (03:00 UT). The bottom side panels of the figure are Keogram of the OHNIR images showing what was going on in the mesosphere. Several wave structures propagating from NW to SE can be seen. Between 23:30 UT and 00:30 UT over zenith, a large 


\begin{tabular}{|c|c|c|c|c|c|c|c|}
\hline No. & Dist.(km) & 21 (UT) & 22 UT & 23 UT & 24 UT & 25 UT & 26 UT \\
\hline B1 & \#\# & & & & & & \\
\hline B2 & 124 & & & & & & \\
\hline B3 & 130 & & & & & & \\
\hline B4 & 178 & & & & & & \\
\hline B5 & 130 & & & & & & \\
\hline B6 & 100 & & & & & $>$ & \\
\hline B7 & 220 & & & & ૧૯ & & 2 \\
\hline GW1 & (52) & & & & & & \\
\hline GW2 & (132) & & & & & 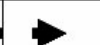 & \\
\hline GW3 & (220) & & & & & & \\
\hline
\end{tabular}

Fig. 5. OI 6300 intensity depletion sequence from B1 to B7 and the mesospheric gravity waves GW1 to GW3 observed at Cariri in the night of 30 September 2005. The arrows indicate the starting time and the duration to observe them in the images. Second column shows a distance between the adjacent depletions, Bn-B(n-1), and the gravity wave horizontal wavelength $(\lambda)$ in $\mathrm{km}$ for GW1-3. The local sunset was 20:48 UT.

amplitude oscillation with a period of about $1 \mathrm{~h}(\mathrm{GW} 3)$ can also be seen. Figure 5 shows the sequence of depletion, as numbered in Fig. 2, from B1 to B7 and their horizontal distances between the adjacent ones (the second column). B5 and B7 are not marked in Fig. 2. The depletions B1 to B5 are comb-like depletion and B6 and B7 are bubble. The starting time indicates when the depletion was observed in the northwestern sky. The imager covers the 6300 emission layer with a horizontal distance of about $1500 \mathrm{~km}$, which corresponds to the zenith angle of $75^{\circ}$. For example, the horizontal distance between the first depletion B1 and the second B2 can be estimated as $124 \mathrm{~km}$. The horizontal distance between the first 5 depletions is about $130 \mathrm{~km}$ on an average. Also shown in Fig. 5, are the mesospheric gravity waves (GW1, GW2, and GW3) observed during the same period, but only for the longer horizontal wavelength $(>50 \mathrm{~km})$. The second column shows their horizontal wavelength. It is interesting to note that the wave activities started to increase after 22:30 UT, prior to the periodic OI 6300 depletion onset in the ionosphere.

From the mesospheric OHNIR images, gravity wave characteristics were calculated using two-dimensional FFT analysis and Keogram. During the passage of the comb-like depletion in the ionosphere, between 22:00 and 23:30 UT, a long gravity wave, with the horizontal wavelength of $135 \mathrm{~km}$, the observed period of $31 \mathrm{~min}$ and the phase velocity of $74 \mathrm{~m} / \mathrm{s}$, propagating towards SE, was observed. This is what was shown in Fig. 3. The gravity wave characteristics retrieved from the $\mathrm{OH}$ images are summarized in Table 1. It is interesting to note that there was a much longer wave, with a horizontal wavelength of $220 \mathrm{~km}$, which was identified by the Keogram analysis. This wave was observed after 23:00 UT and lasted up to 01:00 UT. During this period, the bubbles
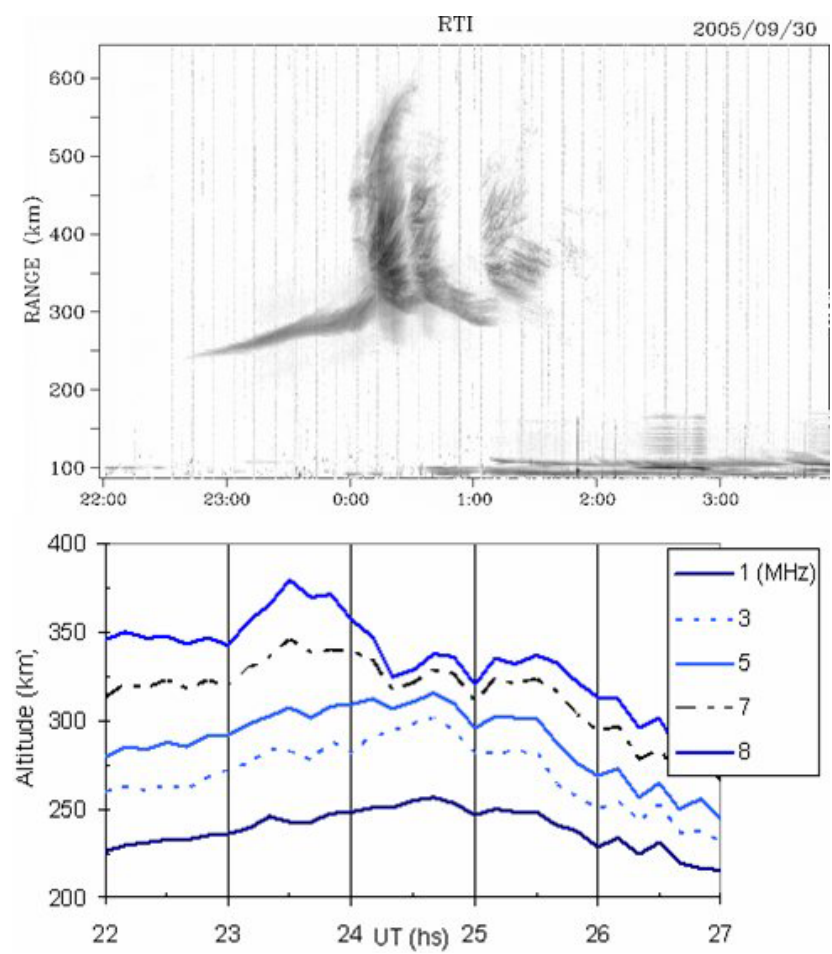

Fig. 6. São Luís VHF radar back scatter (top) and Ionosonde fixed frequency height in the night of 30 September 2005.

with a long N-S extension, B6 and B7, were observed and the distance of B7 to B6 was $220 \mathrm{~km}$.

The F-layer dynamics during the evening of 30 September is shown in Fig. 6. The VHF coherent radar at São Luís showed bottom side backscattering starting from 22:40 UT to 24:00 UT, which was followed by a plume-like bubble 
Table 1. Mesospheric gravity wave characteristics observed at Cariri on 30 September and 1 October 2005, obtained by FFT and KEOGRAM analyses of the OHNIR airglow images.

\begin{tabular}{clllllccc}
\hline Day $(\mathrm{mmdd})$ & $\mathrm{GW}$ & $\lambda(\mathrm{km})$ & $\tau(\mathrm{min})$ & $\mathrm{Vp}(\mathrm{m} / \mathrm{s})$ & Azim. $\left(^{\circ}\right)$ & Start $(\mathrm{UT})$ & End $(\mathrm{UT})$ & Note \\
\hline 0930 & GW1 & 52 & 14 & 60 & 152 & $22: 45$ & $24: 00$ & FFT \\
0930 & GW2 & 135 & 30.7 & 73.7 & 135 & $22: 45$ & $24: 00$ & FFT \\
0930 & GW3 & $220(10)$ & 53 & 69.3 & 138 & $23: 00$ & $25: 00$ & KEOGRAM \\
1001 & GW1 & $143(*)$ & 61 & $39(2)$ & 68 & $21: 10$ & $21: 45$ & FFT \\
1001 & GW2 & 120 & 41 & $48(3)$ & 129 & $21: 45$ & $23: 30$ & FFT \\
1001 & GW3 & $265(20)$ & $64(5)$ & $69(2)$ & 83 & $21: 00$ & $26: 00$ & KEOGRAM \\
\hline
\end{tabular}

Remark: $\lambda$ : horizontal wavelength, $\tau$ : period, Vp: observed phase velocity, Azim.: direction of propagation in degree counting from North. The number in parenthesis is the error range. $(*)$ : wavelength of the train of wave after the bore front.

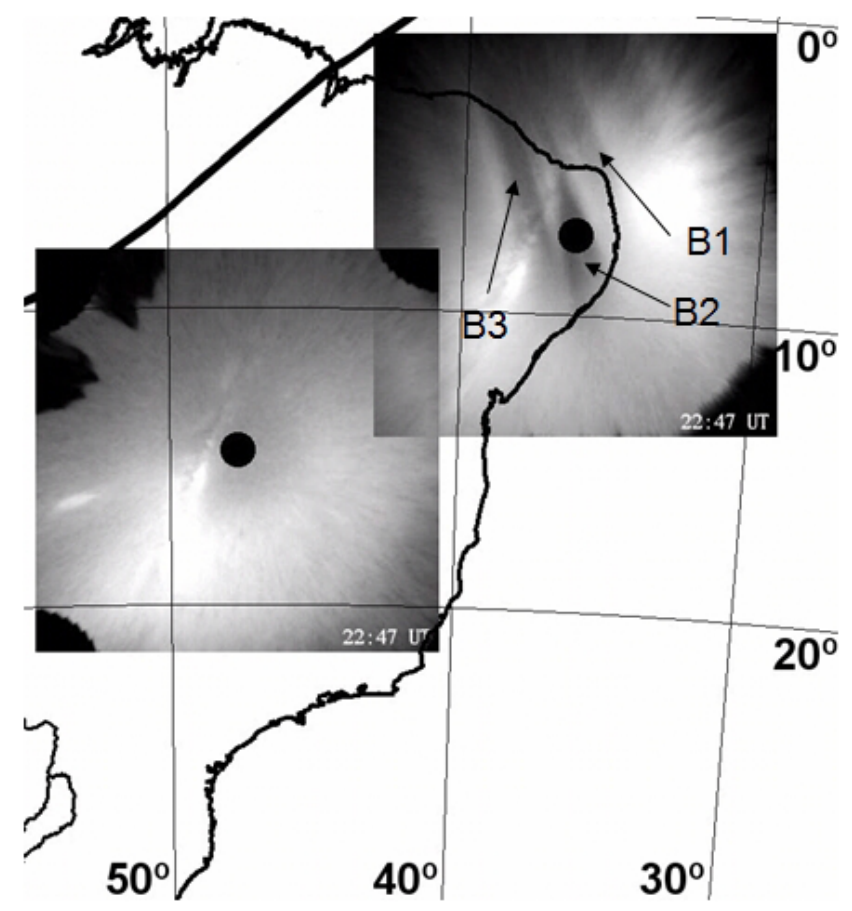

Fig. 7. OI 6300 flatfield images observed at Cariri (top, right) and near Brasilia (bottom, left) at 22:47 UT in the night of 1 October 2005. The black dot is the location of the observation site. The depletions are numbered (see Fig. 9).

structure that grew up from 300 to $600 \mathrm{~km}$ of altitude. The true heights at fixed frequencies (1 to $8 \mathrm{MHz}$ ) as obtained from the sequence of ionograms taken at the same site are also shown in the figure. The lower part of the F-layer (corresponding to $1-5 \mathrm{MHz}$ ) rose upward to 00:40 UT, while the upper part (7-8 MHz, which is close to the peak height) already started to descend after 23:30 UT. Therefore, the Flayer was vertically compressed around 24:00 UT. The high altitude plume is seen at this moment. It is worthwhile to note that the spatially periodic depletions of the OI 6300 intensity observed by the imager and the bottomside scattering layer observed by the coherent radar may be the same phenomenon, i.e., a periodic plasma density oscillation in the bottomside of the F-layer.

\subsection{October 2005}

In the evening of 1 October, the F-layer was uplifted to $400 \mathrm{~km}$ ( $h m \mathrm{~F} 2$ not shown here) at 22:30 UT, earlier than on the previous night (30 September). In Fig. 7, the 6300 flatfield images observed at Cariri and near Brasilia at 22:47 UT are shown, in which the first 3 depletions over Cariri were seen in the northwestern sky. The depletion B1 is relatively less extended and is limited in the northern sky. The depletions B2 and B3 are extended over the zenith at Cariri, indicating that they must be the plasma bubbles. The distance between the bubbles observed at Cariri during this period was around $130 \mathrm{~km}$. It is interesting to note that the bubbles observed at Cariri could not be seen at the site near Brasilia (see also Taylor et al., 2009). It suggests that the first group of bubbles was seeded in a region between Brasilia and Cariri. Keograms of the N-S and E-W directions taken from the Cariri image data are shown in Fig. 8 for 6300 (top) and OHNIR (bottom). After 23:00 UT, two large and well extended bubbles moving eastward were observed. During the same period, OHNIR image also showed a large intensity depression propagating toward the east. From the E-W Keogram this wavelike oscillation (with long period and long horizontal wavelength) started after 22:00 UT and lasted up to 01:00 UT, with three crests. From the N-S Keogram one can notice that both the emissions showed strong intensity depletions at 23:00 and 00:30 UT. The time frame of the bubble and gravity wave occurrence on this night is summarized in Fig. 9. The depletion B1 is a short extended and those of B2-B3 and B5-B6 are long extended ones. The gravity wave GW1 had the form of a wave front (bore) progressing toward NE. Fechine et al. (2009) reported that during the period from 21:00 to 22:00 UT, there was a Doppler ducting condition. After the ducting condition was over (22:00 UT) the long wavelength GW2 and GW3 were observed. It is worthwhile to note that a sporadic E-layer was present during this period. 


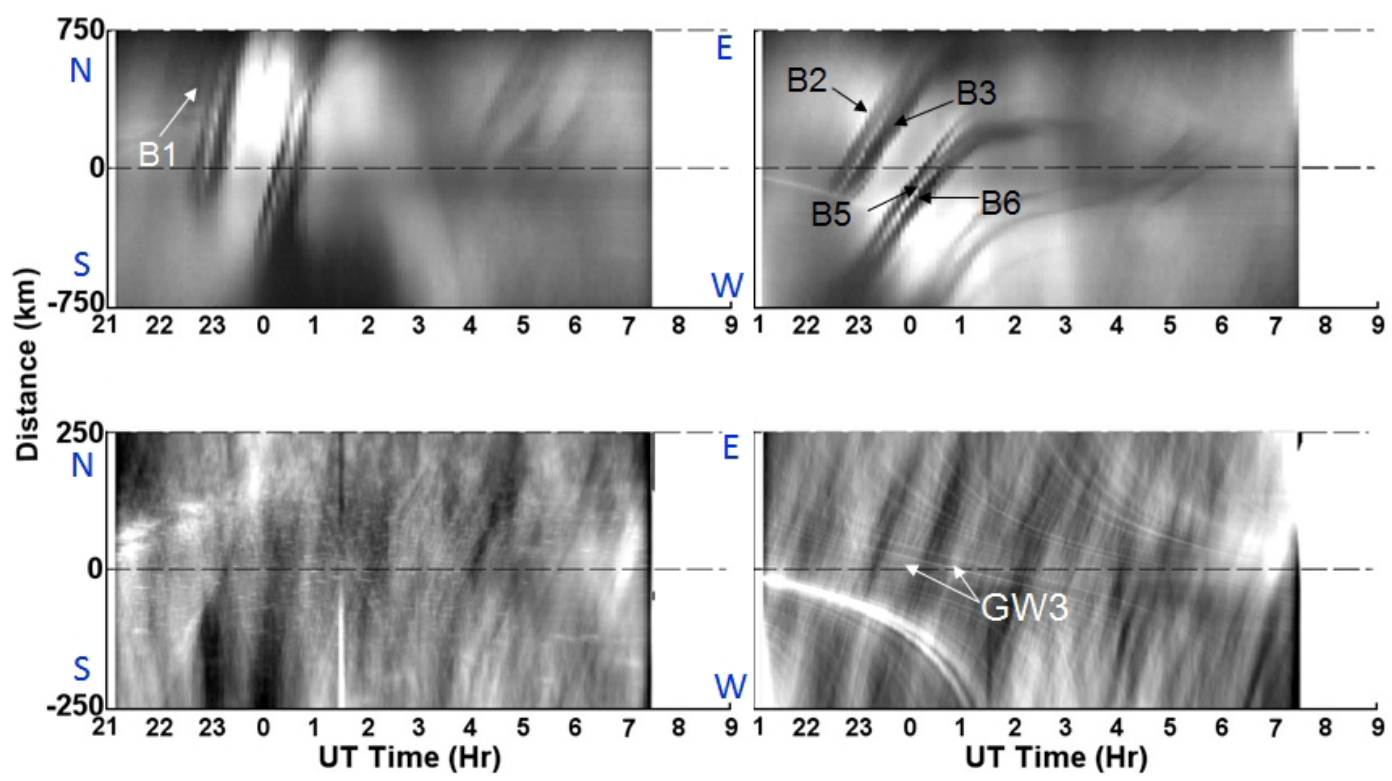

Fig. 8. Keogram of the flatfield images of OI 6300 (top) and OHNIR (bottom) at Cariri on 1 October 2005: N-S cut (leftside) and E-W cut (rightside).

\begin{tabular}{|c|c|c|c|c|c|c|c|}
\hline No. & Dist. (km) & 21 (UT) & 22 UT & 23 UT & 24 UT & 25 UT & $26 \cup T$ \\
\hline B1 & 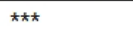 & & 吅 & $>$ & & & \\
\hline B2 & 131 & & प0口 & 5 & & & \\
\hline B3 & 124 & & 吅 & $\Rightarrow$ & & & \\
\hline B4 & 200 & & III & $\Rightarrow$ & & & \\
\hline B5/6 & 180 & & & पिए & & $>$ & \\
\hline B7/8 & 120 & & & & $\square \square$ & 7 & 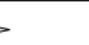 \\
\hline GW1 & $(143 *)$ & - & & & & & \\
\hline GW2 & (120) & & - & $\rightarrow$ & & & \\
\hline GW3 & (265) & & - & - & - & - & - \\
\hline Es & & 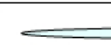 & Es & 9 & & & \\
\hline
\end{tabular}

Fig. 9. OI 6300 intensity depletion sequence from B1 to B8, the mesospheric gravity waves GW1 to GW3, and Sporadic Es-layer observed at Cariri in the night of 1 October 2005. The arrows indicate starting time and the duration to observe in the images. Second column shows a distance between the adjacent depletions, $\mathrm{Bn}-\mathrm{B}(\mathrm{n}-1)$, and the gravity wave horizontal wavelength $(\lambda)$ in km for GW1-3. The local sunset was 20:48 UT. The GW1 is a bore (see text).

The gravity wave characteristics for this evening are summarized in Table 1. Two waves, with horizontal wavelengths of 120 and $143 \mathrm{~km}$, were identified from the FFT analysis (Wrasse et al., 2009). A much longer wave with the wavelength of $265 \mathrm{~km}$ was found by the Keogram.

From the VHF radar RTI image, shown in Fig. 10 (top panel), one could see that the first plume started at around 22:30 UT, with a sequence of 3-4 fine plumes from 22:30 to 23:00 UT and the bottom height coming down from $350 \mathrm{~km}$ to $220 \mathrm{~km}$. The second group of plume started at 00:00 UT and developed to much higher altitude $(\sim 600 \mathrm{~km})$. The fixed frequency true height plot also shown in Fig. 10 (bottom side) presents a downward phase propagation during the first bubble occurrence (22:30-23:00 UT), suggesting a passage of a large scale gravity wave. After 00:00 UT the F-layer was suddenly uplifted by about $50 \mathrm{~km}$. In this case, no time lag between the different frequencies was observed. The two groups of plume observed by both the radar and ionosonde should correspond to the two 6300 depletions observed by the imager, the first one at 23:00 UT and the second one at around 24:20 UT. 

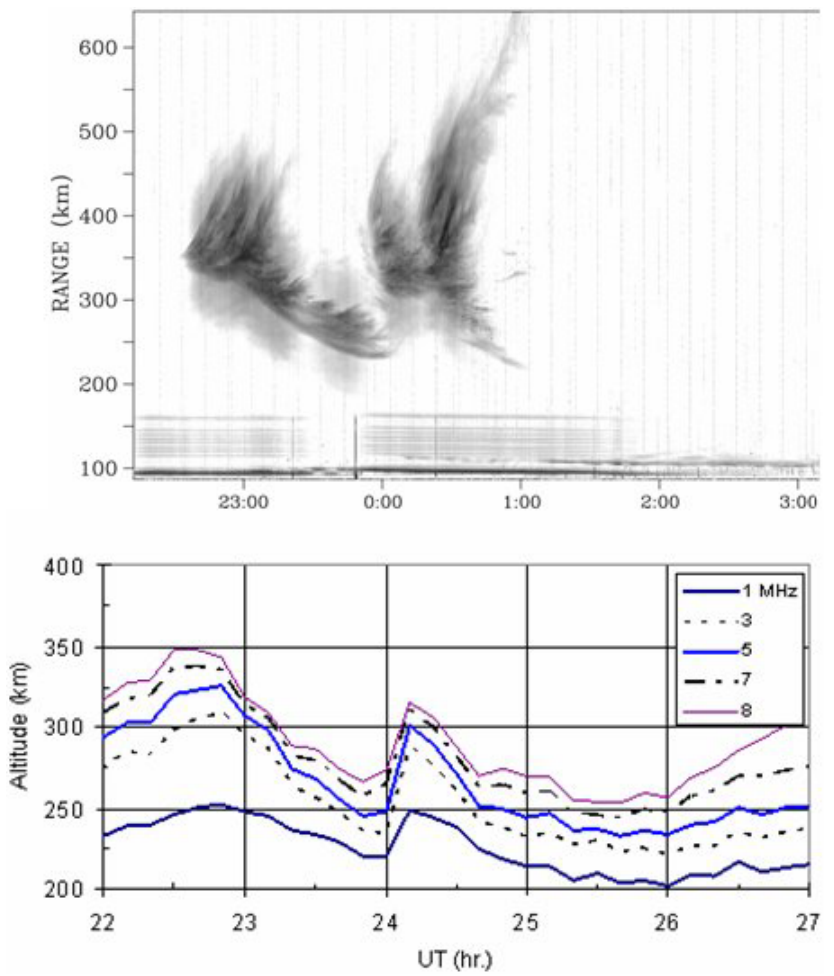

Fig. 10. São Luís VHF radar back scatter (top) and Ionosonde fixed frequency height (bottom) on the night of 1 October 2005.

\section{Discussion}

Similarity: One of the purposes of the present SpreadFEx campaign was to investigate whether there is any evidence on the ionospheric plasma bubble seeding by tropospheric cloud convection activities. It is known that the gravity wave activity in the mesosphere is strongly related to meteorological activities, such as local cloud convections, inter tropical convection zone and squall lines in the equatorial region. Therefore, as a first step, any similarity on the characteristics of the equatorial Spread F and mesospheric gravity waves should be investigated with a special attention. From the ionospheric 6300 and mesospheric OHNIR image data obtained from the two consecutive nights, 30 September and 1 October 2005, it seems that there is a strong similarity between them particularly focusing on the gravity wave horizontal wavelength and the longitudinal distance between the depletions, although the two activities are separated in altitude by almost $150 \mathrm{~km}$. In the case of 30 September, we observed a series of short ranged depletions with a distance of $130 \mathrm{~km}$ between them in the form of sinusoidal oscillation. During this period, a gravity wave in the mesopause with the horizontal wavelength of $135 \mathrm{~km}$ was observed. Similar depletion distances and gravity wave horizontal wavelengths were observed on the evening of 1 October 2005, too. Similarities between the two phenomena seem to be clear in Figs. 5 and 9.
Difference: There is a difference between what was observed on 30 September and on 1 October. The periodic depletions observed on 30 September did not develop vertically for more than one hour before the start of the bubble that occurred only after 24:00 UT. On the other hand, the depletions observed on 1 October turned to the bubbles soon after 22:40 UT. There should be several factors to be considered on the difference. One of the reasons might be that the RTI growth condition must not be sufficient on the evening of 30 September. It could happen if the amplitude of the plasma density perturbation was not large enough to develop RTI. From the point of view of the plasma density modulation by gravity waves, one of the factors would be the gravity wave propagation direction in relation to the local geomagnetic field line. Whether the gravity wave phase front is parallel to the magnetic field line or perpendicular could make a difference in the effectiveness of the plasma density perturbation. In the case of 30 September, the GW2 propagated towards SE ( $135^{\circ}$ of azimuth). The wave front, therefore, makes an angle of $65^{\circ}$ against the field line $\left(-20^{\circ}\right.$ at Cariri). On the other hand, the GW2 wave front on 1 October made an angle of $25^{\circ}$ with the field line. The latter might be more efficient to produce the plasma density modulation than the former assuming that both have the same intensity. Further quantitative discussions would require an atmospheric model including the ionospheric dynamics.

Gravity waves in the ionosphere: Direct influence of the gravity wave in seeding the ionospheric bubbles has been discussed by several authors. Singh et al. (1997) presented plasma bubble development from wavy ion density structures in the bottom side of the F-layer, and suggested that gravity waves seed the bubbles. They further noted that the spacing between the bubbles is closely related to the gravity wave horizontal wavelength. As mentioned before, Hysell et al. (1990) demonstrated direct evidence of the bubble seeding by the gravity wave in the bottom side of the F-layer where significant bubble activity took place under the influence of a magnetic storm induced electric field. Lin et al. (2005) analyzed the IMAGE and ROCSAT-1 satellite data and reported that the plasma bubble eastward drift velocity is faster than the background plasma drift, and rather to be consistent with the zonal speed of gravity wave propagation. They concluded that the gravity waves have an important role, not only for initiating plasma bubbles but also for maintaining the horizontal motion of equatorial plasma bubbles. Abdu et al. (2009) and Kherani et al. (2009) have provided some cases showing evidence for direct GW seeding of the RTI and spread $\mathrm{F}$ generation as diagnosed by the $30 \mathrm{MHz}$ radar and the Digisonde at São Luís. Our present results support these recent works and further demonstrate a coupling between the mesospheric gravity waves and plasma bubbles.

Gravity wave vs. plasma bubble: In order to see the relation between the mesospheric gravity waves and the plasma depletions and/or bubbles we analyzed the gravity waves and depletions for another 15 nights of data. In Fig. 11, we 
plot the observed gravity wave horizontal wavelengths and OI 6300 depletion distances. Each plot corresponds to a couple of data selected with a criteria of (1) limiting a time zone from 19:00 to 21:00 LT (22:00-24:00 UT) for both the depletions and mesospheric gravity wave activity in order to see the initial phase of the depletion formation, and (2) selecting gravity waves with the wavelength longer than $50 \mathrm{~km}$ as a candidate. According to Vadas (2007), the gravity waves able to penetrate the thermosphere should have a horizontal wavelength between 40 and $250 \mathrm{~km}$ and a vertical wavelength between 25 and $65 \mathrm{~km}$. For a selected gravity wave during a certain time interval the distance of the depletions is not always unique. There could have been more than one. In this case, all of the distances were plotted against the gravity wave selected for that time interval. Figure 11 shows the plot for 23 cases on the total of the 17 nights selected for the present analysis. The figure shows a strong linear regression with the correlation coefficient higher than 0.7. For a $200 \mathrm{~km}$ of depletion distance, for example, one can see the gravity wave horizontal wavelength of $\sim 200 \mathrm{~km}$. This result strongly suggests that the mesospheric gravity wave horizontal wavelength might have a special significance in the plasma bubble zonal distribution.

There should have been several conditions for the mesospheric gravity waves to contribute in the bubble formation. Firstly, the wave should penetrate into the F-layer bottom height and kick off RTI during the period of F-layer uplifting. Secondly, the gravity wave should have sufficient amplitude of oscillation (wind or density) to trigger the RTI. Thirdly, the gravity wave phase speeds are sufficient to get a resonance condition for coupling of a wave and plasma process (Vadas, 2007). The direction of the gravity wave propagation, with respect to the magnetic field line, might also be important for plasma density perturbation, as mentioned before. From the present study, only the first condition was investigated. For the second and third conditions, further discussions would be necessary (Fritts and Vadas, 2008).

Ray tracing: In addition to the possibility of direct penetration of gravity waves to the F-layer bottom height (250 to $350 \mathrm{~km}$ ) and generating RTI, a contribution of the E to Fregion electric field perturbation by the neutral atmosphere perturbations should also be investigated. In order to study possible penetration of the mesospheric gravity wave into the lower thermosphere, we used forward ray tracing (Vadas and Fritts, 2009) of the observed gravity waves for the night of 30 September 2005 (Table 1). The wind profile in the mesopause region was used from the observed meteor radar at the same location (Cariri). The temperature and wind profiles below $30 \mathrm{~km}$ were obtained from the balloon sounding, the TIME-GCM model for above $110 \mathrm{~km}$ in the thermosphere. The results showed that the momentum flux of the GW2 (horizontal wavelength of $135 \mathrm{~km}$ ) reached over $160 \mathrm{~km}$ of altitude. This suggests that the observed gravity wave could modulate the plasma field up to $160 \mathrm{~km}$ and generate a local electric field. This electric field would immedi-

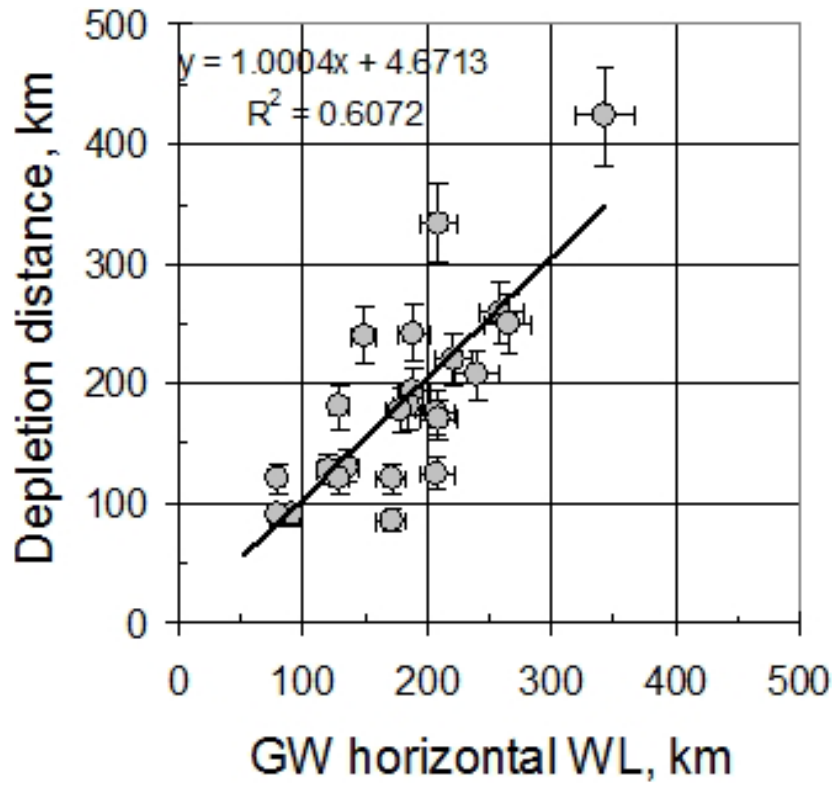

Fig. 11. Distance between the OI 6300 depletions vs. mesospheric gravity wave $(\mathrm{GW})$ horizontal wavelengths (WL). The error bars show the error range in calculating the distance and wavelength from the airglow images.

ately extend along the magnetic field line. Therefore a contribution of the perturbed electric field in the lower thermosphere could be one of the possible seeding processes. On the other hand, one must carefully investigate whether the amplitude of the induced electric field is sufficient to seed RTI and subsequent development of the bubbles.

\section{Conclusion}

During the SpreadFEx Campaign 2005, we observed equatorial plasma bubble formation and development by means of airglow OI 6300 all-sky imager. Simultaneous observation of the $\mathrm{OH}$ and $\mathrm{OI} 6300$ airglow made it possible to investigate possible relation between the bubble seeding in the ionosphere and gravity wave activity in the mesosphere. On the evening of 30 September 2005, comb-like OI 6300 depletions with an equi-distance of $\sim 130 \mathrm{~km}$ between adjacent structures were observed. During this period the F-layer bottom side was disturbed, although the perturbation did not develop upwards not forming high altitude plasma bubbles. During the same period, the mesospheric gravity wave with a horizontal wavelength of $\sim 130 \mathrm{~km}$ and with the observed phase velocity of $74 \mathrm{~m} / \mathrm{s}$ propagating towards the southeast was observed. On the evening of 1 October 2005, a similar inter-bubble distance $(\sim 120 \mathrm{~km})$ and a mesospheric gravity wave with $120 \mathrm{~km}$ horizontal wavelength were observed. From the 17 nights of observation, a good correlation of mesospheric gravity wave horizontal wavelength and the distance of the 6300 depletions was found. The possibility of the 
gravity wave penetration into the lower thermosphere (100$160 \mathrm{~km}$ ) was examined. The results suggest that the observed ionospheric plasma depletions and bubbles are strongly related to the mesospheric gravity wave activities, mainly with their horizontal wavelengths.

Acknowledgements. The authors thank several institutions and observatory staff who carried out ground-based observations for the present SpreadFEx campaign: São Luís ionospheric observatory (Acacio C. Neto, Lazaro A. P. Camargo, Francisco P. V. Mesquita), Fortaleza ionospheric observatory (Avicena F.), Cariri airglow observatory (J. Augusto Souza) and Cachoeira Paulista observatories (Sinval Domingos). Thanks are also due to Maria Goreti S. Aquino and Angela M. Santos who reduced the ionogram data and Bruno R. Cezario and Vinicius G. Botelho (under FAPESP grants numbers 2007/0074-9 and 2006/05006-3, respectively) for the OI 6300 bubble distances reduction. The SpreadFEx field program and data analysis were supported by NASA under contracts NNH04CC67C and NAS5-02036. The present project was also partially supported by $\mathrm{CNPq}$ (Conselho Nacional de Desenvolvimento Cietífico e Tecnológico).

Topical Editor U.-P. Hoppe thanks two anonymous referees for their help in evaluating this paper.

\section{References}

Abdu, M. A.: Outstanding problems in the equatorial ionospherethermosphere system relevant to spread F, J. Atmos. Solar Terr. Phys., 63(9), 869-884, 2001.

Abdu, M. A., Kherani, E. A., Batista, I. S., de Paula, E. R., Fritts, D. C., and Sobral, J. H. A.: Gravity wave initiation of equatorial spread F/plasma bubble irregularities based on observational data from the SpreadFEx Campaign, Ann. Geophys., in press, 2009.

Alexander, M. J. and Holton, J. R.: A model study in the equatorial stratosphere by convectively induced gravity waves, J. Atmos. Sci., 54, 408-419, 1997.

Fechine, J., Wrasse, C. M., Takahashi, H., Medeiros, A. F., Batista, P. P., Clemesha, B. R., Lima, L. M., Fritts, D. C., Laughman, B., Taylor, M. J., Pautet, P. D., Mlynczak, M. G., and Russell, J. M..: Mesospheric Bore Event during SpreadFEx Campaign, Ann. Geophys., in press, 2009.

Fritts, D. C. and Alexander, M. J.: Gravity wave dynamics and effects in the middle atmosphere, Rev. Geophys., 41(1), 1-46, 2003.

Fritts, D. C. and Vadas, S. L.: Gravity wave penetration into the thermosphere: sensitivity to solar cycle variations and mean winds, Ann. Geophys., 26, 3841-3861, 2008, http://www.ann-geophys.net/26/3841/2008/.

Fritts, D. C., Abdu, M. A., Batista, I. S., Batista, P. P., Buriti, R. A., Clemesha, B. R., Comberiate, J., Dautermann, T., de Paula, E., Fechine, J., Fejer, B., Gobbi, D., Haase, J., Kamalabadi, F., Laughman, B., Lima, P. P., Liu, H.-L., Medeiros, A., Paute, D., São Sabbas, F., Sobral, J. H. A., Stamus, P., Takahashi, H., Taylor, M. J., Vadas, S. L., and Wrasse, C.: The Spread F Experiment (SpreadFEx): Program overview and first results, Earth Planets Space, 60, 1-20, 2008a.

Fritts, D. C., Vadas, S. L., Riggin, D. M., Abdu, M. A., Batista, I. S., Takahashi, H., Medeiros, A., Kamalabadi, F., Liu, H.-L.,
Fejer, B. G., and Taylor, M. J.: Gravity wave and tidal influences on equatorial spread $\mathrm{F}$ based on observations during the Spread F Experiment (SpreadFEx), Ann. Geophys., 26, 32353252, 2008b, http://www.ann-geophys.net/26/3235/2008/.

Fritts, D. C., Abdu, M. A., Batista, I. S., Batista, P. P., Buriti, R. A., Clemesha, B. R., Comberiate, J., Dautermann, T., de Paula, E., Fechine, J., Fejer, B., Gobbi, D., Haase, J., Kamalabadi, F., Laughman, B., Lima, P. P., Liu, H.-L., Medeiros, A., Paute, D., São Sabbas, F., Sobral, J. H. A., Stamus, P., Takahashi, H., Taylor, M. J., Vadas, S. L., and Wrasse, C.: Overview and summary of the Spread F Experiment (SpreadFEx), Ann. Geophys., in press, 2009.

Holton, J. R.: An Introduction to Dynamic Meteorology, 507 pp., Academic, San Diego, Calif., 1992.

Hysell, D. L., Kelley, M. C., Swartz, W. E., and Woodman, R. F.: Seeding and layering of equatorial spread $\mathrm{F}$ by gravity waves, J. Geophys. Res., 95, 17253-17260, 1990.

Kherani, E., Abdu, M., Paula, E., Fritts, D., Sobral, J., and Meneses Jr., F.: The impact of gravity waves rising from convection in the lower atmosphere on the generation and nonlinear evolution of equatorial bubble, Ann. Geophys., in press, 2009.

Labelle, J., Jahn, J.-M., Pfaff, R. F., Swartz, W. E., Sobral, J. H. A., and Abdu, M. A., Muralikrishna, P., and de Paula, E. R.: The Brazil/Guará Equatorial Spread F Campaign: Results of the Large-Scale Measurements, Geophys. Res. Lett., 24(13), 16911694, 1997.

Lin, C. S., Immel, T. J., Yeh, H. C., Mende, S. B., and Burch, J. L.: Simultaneous observations of equatorial plasma depletion by IMAGE and ROCSAT-1 satellites, J. Geophys. Res., 110, A06304, doi:10.1029/2004JA010774, 2005.

McClure, J. P., Singh, S., Bamgboye, D. K., Johnson, F. S., and Kil, H.: Occurrence of equatorial $F$ region irregularities: Evidence for tropospheric seeding. J. Geophys. Res., 103, 29119-29135, 1998.

Muralikrishna, P. and Abdu, M. A.: Rocket measurements of ionospheric electron density from Brazil in the last two decades, Adv. Space Res., 37(5), 1091-1096, 2006.

Ogawa, T., Otsuka, Y., Shiokawa, K., Saito, A., and Nishioka, M.: Ionospheric disturbances over Indonesia and their possible association with atmospheric gravity waves from the troposphere, J. Meteorol. Soc. Japan, 84A, 327-342, 2006.

Röttger, J.: Wave-like structures of large-scale equatorial spread-F irregularities, J. Atmos. Terr. Phys., 35, 1195-1206, 1973.

Röttger, J.: Travelling disturbances in the equatorial ionosphere and their association with penetrative cumulus convection. J. Atmos. Terr. Phys., 39, 987-998, 1977.

Röttger, J.: Equatorial spread-F by electric fields and atmospheric gravity waves generated by thunderstorms, J. Atmos. Terr. Phys., 43, 453-462, 1981.

Singh, S., Johnson, F. S., and Power, R. A.: Gravity wave seeding of equatorial plasma bubbles, J. Geophys. Res., 102, 7399-7410, 1997.

Sobral, J. H. A., Abdu, M. A., Takahashi, H., Taylor, M. J., de Paula, E. R., Zamlutti, C. J., and Borba, G. L.: A Study of the ionospheric plasma bubbles climatology over Brazil, based on 22 Years (1977-1998) of OI $630 \mathrm{~nm}$ airglow observation, J. Atmos. Terr. Phys., 64(12-14), 1517-1524, 2002.

Taylor, M. J., Pautet, P.-D., Medeiros, A. F., Buriti, R., Fechine, J., 
Fritts, D. C., Vadas, S. L., Takahashi, H., and São Sabbas, F. T.: Characteristics of mesospheric gravity waves near the magnetic equator, Brazil, during the SpreadFEx campaign, Ann. Geophys., 27, 461-472, 2009,

http://www.ann-geophys.net/27/461/2009/.

Vadas, S. L. and Fritts, D. C.: Thermospheric responses to gravity waves arising from mesoscale convective complexes, J. Atmos. Solar-Terr. Phys., 66, 781-804, 2004.

Vadas, S.: Horizontal and vertical propagation and dissipation of gravity waves in the thermosphere from lower atmospheric and thermospheric sources, J. Geophys. Res., 112, A06305, doi:10.1029/2006JA011845, 2007.

Vadas, S. L. and Fritts, D. C.: Reconstruction of the gravity wave field from convective plumes via ray tracing, Ann. Geophys., 27, 147-177, 2009, http://www.ann-geophys.net/27/147/2009/.
Woodman, R. F. and LaHoz, C.: Radio observations of F-region equatorial irregularities, J. Geophys. Res., 85, 5447-5466, 1976.

Wrasse, C. M., Nakamura, T., Takahashi, H., Medeiros, A. F., Taylor, M. J., Gobbi, D., Denardini, C. M., Fechine, J., Buriti, R. A., Salatun, A., Suratno, , Achmad, E., and Admiranto, A. G.: Mesospheric gravity waves observed near equatorial and low-middle latitude stations: wave characteristics and reverse ray tracing results, Ann. Geophys., 24, 3229-3240, 2006, http://www.ann-geophys.net/24/3229/2006/.

Wrasse, C. M., Takahashi, H., Fechine, J., Medeiros, A. F., and Bageston, J. V.: Mesospheric Gravity Wave Observations during the SpreadFEX Campaign: Evidence of Tropospheric Sources, Ann. Geophys., in review, 2009. 